\title{
Kronik Pelvik Ağrıya Tamamlayıcı ve Alternatif Yaklaşım
}

\author{
Complementary and Alternative Approach to Chronic Pelvic Pain
}

\section{Huri GÜVEY}

Sakarya Özel Konak Hastanesi Kadın Hastalıkları ve Doğum Kliniği, Sakarya

\begin{abstract}
ÖZ
Kronik pelvik ağrı (KPA) en az 6 ay süren, alt karın bölgesinde veya umbilikusun altında yerleşen fonksiyonel veya psikolojik hastalığa neden olabilen, değerlendirme ve tedavi gerektiren bir ağrıdır. Tedaviye yönelik girişimler, bir tanı olarak KPA tedavisi ve KPA ile ilişkili belli başlı hastalıkların tedavisi etrafinda yoğunlaşır. Semptomatik rahatlama için tanı ve tedavide multidisipliner bir yaklaşımın en etkilisi olduğu görülmektedir. Bu çalışmada KPA tedavisinde, tamamlayıcı ve alternatif tıp tekniklerinin de kullanıldığı psikolojik tedavi gibi girişimlerin kanıtları gözden geçirilmiştir. Maalesef bu konuda yapılmış çok az randomize kontrollü çalışma olduğundan en iyi kanıtı bulmak çok zordur. Refrakter KPA tedavisi için zaman geçtikçe bir tedavi kombinasyonuna ihtiyaç duyulmaktadır. KPA'nın multifaktöriyel doğası hastayla tartışmayı, onunla iyi bir uyum içinde bir partner kadar yakın olmayı ve düzenli takip edilecek bir yönetim planı geliştirmeyi gerektirir. Kadınlarda KPA yönetiminde tamamlayıcı ve alternatif tıp tekniklerinin de dahil olduğu multidisipliner bir yaklaşımı teşvik etmek en iyi sonuçları doğuracak gibi görünmektedir.

Anahtar kelimeler: Kronik pelvik ağrı; akupunktur; Çin bitkisel tıbbı; psikoterapi.
\end{abstract}

\section{ABSTRACT}

Chronic pelvic pain (CPP) is defined as pain of at least 6 months' duration that occurs in the lower abdomen or below the umbilicus and has resulted in functional or psychological disability, and required intervention and treatment. Therapeutic interventions center around the treatment of CPP as a diagnosis in and of itself, and treatment of specific disorders that may be related to CPP. A multidisciplinary approach for diagnosis and treatment seems to be most effective for symptomatic relief. The evidence for such interventions as psychological treatments including the use of complementary and alternative medicine techniques for CPP treatment is reviewed in this study. Unfortunately, finding the best evidence in this setting is difficult as very few randomized controlled trials are available. A combination of treatments is usually required over time for the treatment of refractory CPP. The multifactorial nature of CPP needs to be discussed with the patient and a good rapport as well as a partnership needs to be developed to plan a management program with regular follow up. Promotion of a multidisciplinary approach which includes complementary and alternative medicine techniques in managing CPP in women seems to yield the best results.

Keywords: Chronic pelvic pain; acupuncture; Chinese herbal medicine; psychotherapy.

\section{GİİŞ}

Kronik pelvik ağrı (KPA) alt abdomen veya pelviste aralıklı veya süreli olarak olan en az 6 ay süren ağrı olarak tanımlanır (1). \%12 ile \%39 arasında değişen bir prevalansla kadınların yaşadığı en yaygın ağrı durumlarından biridir (2). Tedavi edilmemiş KPA fiziksel rahatsızlığa ek olarak işlev bozukluğu, yaşam kalitesinin düşmesi ve artmış psikolojik hastalık ihtimali dahil bir çok kişisel zarara sebep olur (3). KPA'nın kadınlar üzerindeki etkisi halen elde olan sınırlı tedavi yöntemleri nedeniyle fazladır. KPA tedavilerini etkinliklerini karşılaştırmalı olarak değerlendiren sistematik bir derlemede histerektomi, laparaskopik uterosakral sinir ablasyonu gibi yaygın cerrahi tedaviler ve hormonal tedaviler gibi cerrahi olmayan tedaviler için yeterli kanıt bulunamamıştır (4).

\section{KRONIK PELVIKK AĞRININ NEDENLERİ}

KPA'nın birçok nedeni olsa da birçok kadına kesin tanı konulamamıştır (5) KPA'nın jinekolojik nedenleri arasında endometriozis, adenomiyozis, uterin miyomlar, servikal stenoz, pelvik konjesyon sendromu ve ovaryan kalıntı sendromu, pelvik yapışıklıklar ve pelvik 
inflamatuvar hastalıklar sayılabilirken, iritabl barsak sendromu, kronik kabızlık, intyerstisyel sistit, pudendal nevralji, miyofasiyal ağrı sendromları, pelvik taban kas ağrısı gibi diğer organik nedenler de etiyolojide yer almaktadır. Bunun yanı sıra depresyon, ilaç çekilme sendromları gibi psikolojik durumlar da hastalığa etken olabilmektedir, ancak en sik nedeni endometriozistir (5). KPA tedavisi üzerine çok az randomize kontrollü çalışma yapılmıştır. KPA'nın etiyolojisinin tam anlaşılamaması ve katkıda bulunan birçok muhtemel etken olması nedeniyle tedavi çoğunlukla tatmin edici değildir ve kısmi rahatlamayla sınırlı kalır. Bundan dolayı KPA şikayeti olan kadınların başarılı bir tedavi için çok yönlü bir yaklaşıma ihtiyacı vardır (6). Amerika Birleşik Devletleri'nde yetişkinlerin peşin sağlık giderlerinin \%11,2'si tamamlayıcı ve alternatif tedavi yöntemlerine harcanmaktadır. Birçok tedavi yöntemi olmasına rağmen hassas testler ve iyi planlanmış randomize kontrollü çalışmalar azdır. Beslenme değişiklikleri ve fiziksel tedavi modaliteleri de siklıkla alternatif tedavi kategorisinde yer almaktadır (7). Son zamanlarda KPA'nın biyopsikososyal yönüyle anlaşılması da ağrılarını daha iyi yönetebilmek için insanlara yardım etmek amacıyla birçok psikolojik temelli tedavi yaklaşımların geliştirilmesine yol açmıştır (6).

\section{TEDAVI YAKLAŞIMLARI}

Fred Howard (5) KPA'da tedaviye yönelik girişimlerin bir tanı olarak KPA'nın tedavisi ve KPA ile ilişkili olabilecek belli başlı hastalıkların tedavisi etrafinda yoğunlaştığını ifade etmiştir. Semptomatik rahatlama için tanı ve tedavide multidisipliner bir yaklaşımın en etkilisi olduğu görülmektedir. Howard (5)'a göre KPA'nın genel tedavisi farmasötik, psikolojik ve nöroablatif olarak 3 gruba ayrılabilir. Stones ve ark. (8)'nın yaptığ 1 bir Cochrane derlemesinde birçok değişik girişimleri kullanan çalışmalardan elde edilen sonuç ve bilgileri kombine ederek KPA için en etkili, makul ve en az girişimsel tedavi seçeneklerine genel bir bakış amaçlanmıştır. Yazarlar yaşam tarzı, fiziksel, medikal, cerrahi ve psikolojik tedavi gibi girişimleri içeren çalışmaları göz önüne almışlardır. Sonuç değerlendirme ölçümleri ağrı puanlama skalaları, yaşam kalitesi ölçekleri, ekonomik analizler ve yan etkilerdir. Bu derlemede 19 çalışma tanımlanmış, bunlardan 14 tanesi analize dahil edilmiştir. Yazarların çıkardığı sonuca göre; KPA'nın patofizyolojisi çok iyi anlaşılamadığından dolayı tedavisi genellikle tatmin etmemekte ve memnuniyetsizlikle sonuçlanmaktadır. Günümüzde tedaviye ana yaklaşımlar psikoterapi danışmanlığ ekarte etmek için laparaskopi, medroksiprogesteron asetat gibi progesteron tedavileri ve nöral yolları kesintiye uğratmak için cerrahi uygulamalarını içermektedir. Genel toplumda yaygın kullanımına ve KPA semptomları için potansiyel faydalarına rağmen, KPA yaşayan kadınlar arasında tamamlayıcı sağlık yaklaşımları hakkında çok az şey bilinmektedir (8). Kesitsel çalışmalar perimenapozal kadınların \%60'ında kendilerinin bildirdiği pelvik ağrı dolduğunu (9) ve interstisyel sistiti olan kadınların \%84'ünün tamamlayıcı tedavilerin bazı formlarından kullandığını göstermektedir. $\mathrm{Bu}$ çalışmalar KPA için tamamlayıcı sağlık yaklaşımlarının kullanım sıklığının yüksek olduğunu ancak örneklem tekniğinden dolay1 genellenebilirliğinin sınırlı olduğunu göstermektedir (10).

Her ne kadar konvansiyonel tıp kontrollü klinik çalışmalarla yeni tedavileri belirlemeyi amaçlasa da birçok tamamlayıcı ve alternatif akupunktur ve bitkisel ilaçlar gibi alternatif tedaviler yüzyıllardır yaygın olarak uygulanmaktadır. $\mathrm{Bu}$ uzun süre kaydedilmiş klinik tecrübe farklı bir kanıt türü olarak katkıda bulunur. Çin bitkisel tıbbını inceleyen 20.000'den fazla randomize kontrollü çalışma vardır. Bununla birlikte bu çalışmaların büyük yüzdesi zayıf metodoloji nedeniyle sekteye uğramaktadır ve sonuç olarak bu kanıtların çoğu hala neticesiz kalmaktadır (11). Klinik çalışmalara ek olarak son zamanlarda KPA üzerinde antiinflamatuar ve diğer açılardan fayda sağlayacak biyolojik olarak akla yakın mekanizmalarla ilgili yoğun araştırmalar yapılmaktadır (12).

\section{Akupunktur ve Kronik Pelvik Ağrı}

Akupunktur 2000 yıl önce Çin'de ortaya çıkmış bir sistemdir. İnce iğnelerin vücut yüzeyi üzerinde özellikli, tanımlanmış noktalara uygulanmasını içerir. Bu noktaların uyarılmasının lokal ve sistemil iyileşme cevabını uyardığı düşünülmektedir. Tedavinin sıklığ 1 akut durumlarda 2-3 haftadan, kronik ve uzun süreli durumlarda ayda 1 defaya kadar değişmektedir. Tedavini süresi de bu şekilde değişkendir. Bazı durumlarda 2-3 seans yeterli iken, daha kompleks dirençli durumlarda tedavi aylar sürebilmektedir (13).

Literatürde spesifik olarak KPA tedavisinde akupunktur ile ilgili yapılmış çalışmaya rastlanmamıştır. Ancak KPA'ya katkıda bulunduğu bilinen dismenore, iritable barsak sendromu ve pelvik inflamatuar hastalıklarla ilgili çalışmalar bulunmaktadır (14). Akupunkturun tedavi almayan gruba göre dismenorenin ciddiyetini azalttığına dair kanıtlar mevcuttur (15). Son zamanlarda yapılan bir Cochrane derlemesinde değerlendirilen küçük hasta grubuyla yapılan iki çalışmada akupunktur tedavisinin standart nonsteroidal antiinflamatuar ilaç tedavisiyle kıyaslandığında menstrüel semptomları anlamlı olarak azalttığ görülmüş̧ür (16). İritable barsak sendromunda akupunktur tedavisiyle ilgili yapılan bir Cochrane derlemesinde gerçek ve taklit akupunkturla yapılan karşılaştırmalı bir çalışmada, arada çok az bir fark olduğu her iki tedavide de iritable barsak sendromu bulgularında azalma olduğu görülmüştür (17). Çin'de yapılan çalışmalarda KPA tedavisinde akupunkturun rolünün karşılaştırıldığında Çin bitkisel ilaçları (18) ve antibiyotik tedavisine (13) göre daha öncelikli olarak akılda tutulması gerektiği kanısına varılmıştır. Ancak bu çalışmalar kör çalışmalar olmadığ 1 için taraflılık riski vardır ve yöntem olarak yeterince titiz değildir (13).

\section{Çin Bitkisel Tıbbı ve Kronik Pelvik Ağrı}

Çin bitkisel tıbbı Çin ve diğer doğu Asya ülkelerinde akupunkturun yanında gelişim göstermiştir ve 2000 yıllık bir tarihe dayanmaktadır. Semptomlar ve altta yatan hastalığ 1 tedavi etmek amacıyla bitkisel bir formül hazırlanır (14). Tedavi haşlanarak hazırlanarak veya bitkisel çorba olarak, konsantre tozlar, bitkisel haplar, alkolik tentürler şeklinde uygulanabilir. Endometriozsite Çin bitkisel tıbbı uygulamalarıyla ilgili bir Cochrane derlemesinde cerrahi sonrası Çin bitkisel tıbbı uygulamasının antiprogestin ajan gestrinonla kıyasalanbilir faydaları olduğu, dismenoreyi azaltmada anlamlı düzeyde etkilerinin bulunduğu ve pelvik lezyonların kaybolmasında danazolden daha etkili olduğu, ancak klasik tedavilere göre daha az yan etkisi olduğu sonucu çıkarılmıştır (19). Endometriozisi olan ve Çin bitkisel tıbbı uygulamalarıyla birlikte hipnoterapi alan 47 kadının dahil edildiği retrospektif bir çalışmada ağrı ve analjezik kullanımında anlamlı derecede azalma tespit edilmiştir (13). Çin bitkisel tıbbının dismenore üzerindeki etkilerini inceleyen 39 randomize kontrollü çalışmanın dahil edildiği bir Cochrane derlemesinde nonsteroidal antiinflamatuar ilaçlar ve oral kontraseptiflerle kıyaslandığında Çin bitkisel tıbbi uygulamaları lehine olumlu sonuçlar elde edilmiştir. $\mathrm{Bu}$ derlemede Çin bitkisel tıbbi uygulamalarının ağrıda anlamlı azalma ve ek ağrı kesici kullanımında anlamlı azalma sağladığı vurgulanmıştır. Bununla birlikte bu derlemede yöntemsel kalitesi iyi olmayan küçük örneklemli çalışmalar değerlendirildiği için sonuçlar şüpheyle yorumlanmaktadır (20). Bununla birlikte Çin bitkisel tıbbının biyolojik olarak akla yatkın immünolojik ve antiinflamatuar etkilerini tanımlamak için yürütülen çalışmalar giderek artış göstermektedir $(21,22)$.

\section{Psikoterapi}

Psikoterapi KPA'ya multidisipliner yaklaşımın bir parçası olarak görülebilir. Birçok çalışmada etkisi az olarak belirtilse de psikoterapinin pelvik ağrı ve diğer ağrı sendromlarında iyileşme sağladığ 1 belirtilmiştir. Psikoterapi danışmanlık, grup terapisi, bilişsel davranışsal terapi ve biyofeedback olarak uygulanabilir (23). Somatokognitif tedavinin pelvik ağrı tedavisinde kullanımı 
son yapılan randomize kontrollü çalışmalarda değerlendirilmiştir. Standart jinekolojik bakımla birleştirildiğinde KPA'sı olan kadınlarda somatokognitif terapinin, psikolojik stres, ağrı ve motor fonksiyonlarda iyileşme sağladığı gözlemlenmiştir (24).

\section{Davranışşal Tedavi}

Bilişsel davranış tedavisi sayesinde hastalar ağrıyla daha iyi baş etme yolları geliştirebilir ve kronik ağrılarıyla ilgili ağrı algısını değiştirebilirler. Çalışmalar bu değişikliklerin umutsuzluğu azaltma ve algı kontrolünü artırma konusunda katkıda bulunarak olumlu tedavi sonuçları sağladığını göstermiştir. Bir Cochrane derlemesinde primer ve sekonder dismenore tedavisinde, plasebo, tedavisiz grup ve klasik medikal tedavi gruplarının birbiriyle karşılaștırılarak yapılan çalıșmalarda davranışsal girişimlerin etkinliğinin tespit edilmesi amaçlanmıştır. $\mathrm{Bu}$ derlemede progresif kas gevşemesinin ağrı periyodunun spazmodik bulgularına iyi geldiği gösterilmiştir. Ağrı yönetimi çalışmalarına ek olarak biofeedback ile gevşemenin genel olarak ağrıya iyi geldiği saptanmıştır. Bununla birlikte neticeler çalışmalardaki küçük hasta örneklemlerinden elde edilmiş olması ve yöntemsel kalitenin düşük olması sebebiyle kesin sonuç vermemektedir (25).

\section{Zihin-Beden Tedavisi (Antistres Tedavi)}

Amerikan Ulusal Tamamlayıcı ve Alternatif Tip Merkezi zihinbeden tedavisini vücut fonksiyon ve belirtilerini artırmak için zihnin kapasitesini artırmayı amaçlayan bir dizi tedavi grubu olarak tanımlamaktadır (26). Zihin-beden tedavilerinin KPA'nın yönetiminde etkin olduğu fikir birliğine rağmen hastaların sadece \%20'si bu tedaviyi kullandığını belirtmiştir (27).

\section{Dikkat Meditasyonu}

Dikkat temelli stres azaltma (Mindfulness-based stress reduction, MBSR) KPA'y1 tedavi etme ve buna bağlı gelişen fiziksel fonksiyon ve psikolojik iyilik halini sağlamada etkili olduğu düşünülen bir müdahaledir (28). MSBR'nin temelini yoğun bir dikkat meditasyonu çalışması ve bunun günlük yaşam, stres, hastalık ve ağrıyla başa çıkma konusundaki uygulamaları oluşturur (29). Araştırmalar daha yüksek dikkat seviyesi olan insanların daha fazla duygusal farkındalık, anlayış, kabullenme ve kötü duygu durumlarını düzeltebilme erdemini kullanarak iyilik hislerini daha iyi düzenleyebildiklerini göstermiştir (30). Dikkat meditasyonunun stresle ilişkili medikal durumlar üzerinde tedavi edici etkilerinin olduğunu gösteren pek çok bilimsel kanit mevcuttur (28). Teorik olarak KPA'sı olanlar dikkat meditasyonundan çeşitli yollardan fayda görebilir. Birinci olarak ağnı algısının duyusal ve efektif yönleri dikkat meditasyonunun self regülasyon özelliğiyle düzenlenebilir (31). Merkezi sinir sistemi ağrı algılama yolları olan amigdala ve anterior singulat korteks dikkat meditasyonunun ileri seviyeleriyle inhibe edilebilir (32). İkinci olarak bilişsel davranış terapilerinde olduğu gibi dikkat meditasyonu ağrı algısını artıran sıkıntılı düşünce ve duygulara karşı tepkiyi azaltmayı amaçlar (33). Bir diğer yol ise dikkat meditasyonunun hastalık anksiyetesi, depresyon gibi psikolojik belirtileri azaltmasıdır (34).

\section{Diğer Tedaviler}

Kas iskelet sisteminin KPA oluşumu ve algısında katkısı olduğu ve KPA's1 olanların \%80'inde kas iskelet sistemi disfonksiyonu mevcudiyeti bilinmektedir. Manuel tedavi, elle miyofasiyal gevşeme, ögremeye özgü germe egzersizleri ve biyofeedbeck gibi fiziksel tedavi çeşitleri KPA'sı olan hastalar için güvenli ve etkili bir tedavi seçeneği sunar (6).

Levator ani kası hassasiyetinden kaynaklanan KPA'da Thiele masajının çok faydalı olduğu gösterilmiştir. Thiele masajı levator ani, internal obturator ve piriformis kaslarının transvajinal masaj tekniğidir. Yapılan çalıșmada hastalara 4 hafta boyunca haftada bir kez 5 dakika Thiele masajı uygulanmış ve sonuçları medyan gerginlik skorunun izlemler boyunca azaldığını göstermiştir. Görsel ağrı skorlarında da benzer şekilde anlamlı olarak azalma saptanmışırır (36).

\section{SONUÇ}

Maalesef bu konudaki randomize kontrollü çalışmaların az olmasından dolayı KPA tedavisiyle ilgili iyi düzeyde kanıt bulmak zordur. İncelenen çalışmaların esas kısıtlaması örneklem boyutlarının küçük olması, randomizasyon olmaması ve izlem grubu kadar uygun kontrol grubunun seçilmemesidir. Tedaviye yanıtsız KPA için zamanla farklı tedavi kombinasyonlarına ihtiyaç olmuştur. KPA'nın multifaktöriyel doğası hastayla tartışmayı ve onunla bir partner gibi yakın olmayı ve düzenli takip edilecek bir yönetim planı geliştirmeyi gerektirir. KPA'sı olan kadınlarda tamamlayıc1 ve alternatif tedaviler gibi multidisipliner bir yaklaşımın desteklenmesi iyi sonuçlar vermektedir. Bununla birlikte bu yaklaşımların çok azı klinik çalışmalarda değerlendirilmiştir. Fakat bu tedavilerin KPA'da yaşam kalitesini, ağrıyla başa çıkmayı desteklediği ve ağrıyla ilişkili fonksiyon kaybını da azalttığı bilinmektedir.

\section{KAYNAKLAR}

1. Williams RE, Hartmann KE, Steege JF. Documenting the current definitions of chronic pelvic pain: Implications for research. Obstet Gynecol. 2004;103(3):686-91.

2. Jamieson DJ, Steege JF. The prevalence of dysmenorrhea, dyspareunia, pelvic pain, and irritable bowel syndrome in primary care practices. Obstet Gynecol. 1996;87(1):55-8.

3. Tripoli TM, Sato H, Sartori MG, de Araujo FF, Girao MJ, Schor E. Evaluation of quality of life and sexual satisfaction in women suffering from chronic pelvic pain with or without endometriosis. J Sex Med. 2011;8(2):497-503.

4. Andrews J, Yunker A, Reynolds W, Likis F, Sathe N, Jerome R. Noncyclic chronic pelvic pain therapies for women: comparative effectiveness. Rockville, MD: Agency for Healthcare Research and Quality (AHRQ); 2012. Publicaton No. 11(12)-EHC088-EF.

5. Shin JH, Howard FM. Management of chronic pelvic pain. Curr Pain Headache Rep. 2011;15(5):377-85.

6. Won HR, Abbott J. Optimal management of chronic cyclical pelvic pain: An evidence-based and pragmatic approach. Int J of Womens Health. 2010;2(1):263-77.

7. Leong FC. Complementary and alternative medications for chronic pelvic pain. Obstet Gynecol Clin North Am. 2014;41(3):503-10.

8. Stones RW, Mountfield J. Interventions for treating chronic pelvic pain in women. Cochrane Database Syst Rev. 2000;(4):CD000387.

9. O'Hare PG, Hoffmann AR, Allen P, Gordon B, Salin L, Whitmore K. Interstitial cystitis patients' use and rating of complementary and alternative medicine therapies. Int Urogynecol J. 2013;24(6):977-82.

10. Wang G, Mao B, Xiong ZY, Fan T, Chen XD, Wang L, et al. The quality of reporting of randomized controlled trials of traditional Chinese medicine: A survey of 13 randomly selected journals from mainland China. Clin Ther. 2007;29(7):1456-67.

11. Borchers AT, Hackman RM, Keen CL, Stern JS, Gershwin ME. Complementary medicine: A review of immunomodulatory effects of Chinese herbal medicines. Am J Clin Nutr. 1997;66(6):1303-12.

12. Napadow V, Ahn A, Longhurst J, Lao L, Stener-Victorin E, Harris R, et al. The status and future of acupuncture mechanism research. J Altern Complement Med. 2008;14(7):861-9.

13. Wang XM. On the therapeutic efficacy of electric acupuncture with moxibustion in 95 cases of chronic pelvic infectious disease (PID). J Tradit Chin Med. 1989;9(1):21-4.

14. Royal College of Obstetricians and Gynaecologists (RCOG). Acupuncture and Chinese herbal medicine for women with 
chronic pelvic pain. London: RCOG; 2012. Scientific Impact Paper No. 30.

15. Witt CM, Reinhold T, Brinkhaus B, Roll S, Jena S, Willich SN. Acupuncture in patients with dysmenorrhea: A randomized study on clinical effectiveness and costeffectiveness in usual care. Am J Obstet Gynecol. 2008;198(2):166.e1-8.

16. Smith CA, Zhu X, He L, Song J. Acupuncture for primary dysmenorrhoea. Cochrane Database Syst Rev. 2011;19(1):CD007854.

17. Lim B, Manheimer E, Lao L, Ziea E, Wisniewski J, Liu J, Berman B. Acupuncture for treatment of irritable bowel syndrome. Cochrane Database Syst Rev. 2006;18(4):CD005111.

18. Zhen HL, Wang Y, Liu XJ. Observation of the therapeutic effect of warming needle moxibustion on chronic pelvic inflammation of cold-damp stagnation type. Zhongguo Zhen Jiu. 2008;28(10):736-8.

19. Flower A, Liu JP, Chen S, Lewith G, Little P. Chinese herbal medicine for endometriosis. Cochrane Database Syst Rev. 2009;8(3):CD006568.

20. Zhu X, Proctor M, Bensoussan A, Smith CA, Wu E. Chinese herbal medicine for primary dysmenorrhoea. Cochrane Database Syst Rev. 2007;17(4):CD005288.

21. Shen BQ, Situ Y, Huang JL, Su XM, He WT, Zhang MW, et al. A clinical study on the treatment of chronic pelvic inflammation of Qi-stagnation with blood stasis syndrome by Penyangqing capsule. Chin J Integr Med. 2005;11(4):249-54.

22. Zhang Q, He J, He S, Xu P. Clinical observation in 102 cases of chronic pelvic inflammation treated with qi jie granules. J Tradit Chin Med. 2004;24(1):3-6.

23. Martin CE, Johnson E, Wechter ME, Leserman J, Zolnoun DA. Catastrophizing: A predictor of persistent pain among women with endometriosis at 1 year. Hum Reprod. 2011;26(11):3078-84.

24. Eccleston C, Palermo TM, Williams AC, Lewandowski A, Morley S. Psychological therapies for the management of chronic and recurrent pain in children and adolescents. Cochrane Database Syst Rev. 2009;15(2):CD003968.

25. Proctor ML, Murphy PA, Pattison HM, Suckling J, Farquhar CM. Behavioural interventions for primary and secondary dysmenorrhoea. Cochrane Database Syst Rev. 2007:18(3):CD002248.

26. Butler AC, Chapman JE, Forman EM, Beck AT. The empirical status of cognitive-behavioral therapy: a review of meta-analyses. Clin Psychol Rev. 2006;26(1):17-31.

27. National Center for Complementary and Alternative Medicine (NCCAM). Mind-body medicine: An overview. Maryland: NCCAM; 2007. NCCAM no. D239.

28. Teixeira M. E. Meditation as an intervention for chronic pain: An integrative review. Holist Nurs Pract. 2008;22(4):225-34.

29. Shapiro SL, Oman D, Thoresen CE, Plante TG, Flinders T. Cultivating mindfulness: effects on well-being. J Clin Psychol. 2008;64(7):840-62.

30. Zeidan F, Grant JA, Brown CA, McHaffie JG, Coghill RC. Mindfulness meditation-related pain relief: Evidence for unique brain mechanisms in the regulation of pain. Neurosci Let. 2012;520(2):165-73.

31. Lutz A, Slagter HA, Dunne JD, Davidson RJ. Attention regulation and monitoring in meditation. Trends Cogn Sci. 2008;12(4):163-9.

32. Kingston J, Chadwick P, Meron D, Skinner TC. A pilot randomized control trial investigating the effect of mindfulness practice on pain tolerance, psychological wellbeing, and physiological activity. J Psychosom Res. 2007;62(3):297-300.

33. Chiesa A, Serretti A. Mindfulness-based interventions for chronic pain: A systematic review of the evidence. J Altern Complement Med. 2011;17(1):83-93.
34. Baer RA, Smith GT, Lykins E, Button D, Krietemeyer J, Sauer $\mathrm{S}$, et al. Construct validity of the five facet mindfulness questionnaire in meditating and nonmeditating samples. Assessment. 2008;15(3):329-42.

35. Montenegro ML, Mateus-Vasconcelos EC, Candido dos Reis FJ, Rosa e Silva JC, Nogueira AA, Poli Neto OB. Thiele massage as a therapeutic option for women with chronic pelvic pain caused by tenderness of pelvic floor muscles. J Eval Clin Pract. 2010;16(5):981-2. 